\title{
Transbordeur: uma nova revista internacional sobre fotografia
}

Resenha de: Transbordeur. Photographie, Histoire, Société, Paris, n. 1, 2017.

HELIANA ANGOTTI-SALGUEIRO'

Universidade Presbiteriana Mackenzie / São Paulo, SP, Brasil

Transbordeur. Photographie, Histoire, Société é a nova revista anual apoiada por universidades e órgãos de fomento suiços e publicada pela editora Macula, em janeiro de 2017 em Paris, sob a direção de dois historiadores da arte especializados na área, Olivier Lugon e Christian Joschke, ${ }^{2}$ respectivamente professores nas Universidades de Lausanne e Paris-Nanterre. Trata-se de um belo volume de 235 páginas ilustradas (c. de 78 a cores e 56 pb), com esmerado cuidado gráfico, apresentando 15 artigos que se dividem em três seções: a primeira compõe-se de oito ensaios que fazem parte de um dossiê temático sobre Museus de fotografias documentais; segue-se uma seção sobre Coleções fotográficas (com descrição e análise de três arquivos), e depois a seção Varia, que apresenta quatro artigos traduzidos, assinados por pesquisadores internacionais. A seção final, Leituras, traz resenhas de onze obras recentes da área.

Editorial explica o título da revista como uma evocação da ponte transbordeur de Marselha, construída em 1905 e destruída pelos alemães em 1944 - o substantivo pont transbordeur (masculino em francês) traduz-se como ponte levadiça ou plataforma móvel, para transbordo de passageiros e mercadorias

\begin{abstract}
1. Historiadora da arte pela EHESS de Paris, e ex-Titular da Chaire Brésilienne de Sciences Sociales Sérgio Buarque de Holanda (Maison des Sciences de l'Homme), atualmente pesquisadora em história do urbanismo junto ao PPGAU da Universidade Presbiteriana Mackenzie. Email: <heliana.angotti8@ gmail.com>.
\end{abstract}

2. Ver a obra de referência de LUGON, Olivier, Le style documentaire. D'Auguste Sander à Walker Evans 1920-1945. Paris: Macula, 2001 (além das traduções, a $4^{\mathrm{a}}$ edição francesa saiu em 2017), e La photographie en Allemagne, antbologie de textes (1919-1939). Nîmes: Ed. Jacqueline Chambon, 1997. Em português, "Séries, sequências e pranchas-contato. In: ANGOTTI-SALGUEIRO, Heliana (ed.). O olbo fotográfico. Marcel Gautherot e seu tempo. São Paulo: MAB-FAAP, 2007, p. 290-330. Versão em inglês: Series, sequences and contact-sheets, id., p. 398-401. E de JOSCHKE, Christian, Les yeux de la Nation. Photographie amateur dans 
l'Allemagne de Guillaume II. Dijon/ Union européenne: Les Presses du réel, 2013, e La Guerre 14-18. Arles: Actes Sud, 2014.

3. As expressões entre aspas do texto correspondem todas às do Editorial da revista Transbordeur, n. 1, 2017, p.3-5. de uma margem a outra - mas o que importa é seu sentido metafórico sugestivo da linha da revista, segundo seus redatores, ou seja, a representação do "imaginário da mobilidade", da abertura ou "passagem de fronteiras disciplinares": todo um programa de uma nova escrita da história da fotografia. Essa ponte de Marselha, muito fotografada nos anos 1920, objeto de múltiplas experimentações visuais, se destacou como um equipamento privilegiado da tecnologia moderna, sendo difundida como símbolo da materialidade de "uma arquitetura industrial dinâmica e aérea" - sabe-se que infra-estruturas se revelaram fotogênicas para as novas visões fotográficas das vanguardas artísticas da época. $\bigcirc$ historiador da arte Sigfried Gideon a escolheu para a capa de seu primeiro livro sobre a arquitetura moderna (Baven in Frankreich. Baven in Eisen. Baven in Eisenbeton, 1928), e László MoholyNagy, responsável pelo projeto gráfico, passou a valorizar as formas desses dispositivos técnicos como linguagem da cultura visual.

Contrapondo a "tendência majoritária dos estudos de reduzir as imagens a seus simulacros", e a postura ideológica que as enxergava como "expressões de consciências individuais", a história da fotografia vem, há trinta anos, se engajando em uma "guinada material", interessando-se pela sua existência social, técnica e coletiva. Além do "valor icônico"3 das fotografias, que havia sido abusivamente explorado por ensaístas pouco atentos aos seus contextos históricos, a revista visa estudá-las inscritas nas suas dimensões de produção, circulação, usos e práticas sociais, institucionais, regionais, nacionais e internacionais. Importam, igualmente, os mecanismos econômicos, jurídicos e classificatórios relativos ao armazenamento e comunicação dos acervos, que começavam a se formar em torno de 1900; ou seja, o estudo dos museus, bibliotecas, clubs, agências, instituições patrimoniais e pedagógicas - iniciativas variadas que transformavam o significado e o lugar da fotografia.

A profusão de imagens e seu potencial em documentar os vários campos da vida cotidiana - o aumento das práticas de fotógrafos amadores, o registro de identidades locais e distantes, as possibilidades da imprensa ilustrada e o desenvolvimento das ciências humanas -, deram um élan coletivo ao inventário, valorização, gestão e preservação de coleções diversas e dispersas que se formaram na virada do século XX, acolhendo a diversidade das representações que se construíam em vários países e as concepções de história e cultura em cada um deles.

São estas as questões centrais que, sob uma perspectiva transnacional, são levantadas no primeiro número da revista Transbordeur, cujos subtítulos História e Sociedade assumem todo seu sentido; ao enfatizar o estudo de museus e coleções de fotografias documentais, que seus redatores, Lugon e Joschke, conhecem tão bem, a revista abre espaço para uma reflexão que visa mostrar o 
lugar da fotografia em todos os campos das atividades sociais, e não enfocá-la sob um "ponto de vista estritamente estético". ${ }^{4}$

Assim, nos dois últimos séculos, a fotografia conquistou espaço em todas as esferas do conhecimento e da comunicação de nossa sociedade: "escola, ciência, arte, informação, comércio, política, indústria, guerra, transportes", enfim, nos "espaços públicos e privados", religando os "múltiplos domínios da cultura" e interagindo com as outras mídias: o livro, a imprensa, o registro sonoro, a exposição, o filme e outras formas de projeção ao longo da história. ${ }^{5}$

Como em toda obra coletiva que se preze, uma introdução reflexiva assinada por Olivier Lugon, Estelle Sohier e Anne Lacoste pontua detalhadamente as questões de cada artigo do dossiê sobre "Museus de fotografias documentais", religando suas problemáticas e historiando a diversidade dos atores, das coleções, e a pluralidade mesma que o termo fotografia assumiu em várias instâncias a partir do final do século XIX. A mise en scène da nação e do universal é representada por exemplos como os enciclopédicos Archives de la planète, 1912-1931, no Musée Albert-Kahn, em Boulogne-Billancourt, e seus desdobramentos em período de reconhecimento e registro da diversidade etnográfica e do desenvolvimento da consciência geográfica ou da "apropriação do mundo". ${ }^{6}$ A complexidade da formação de acervos em bibliotecas, museus e demais instituições patrimoniais são analisadas em países diferentes e em situações documentais precisas e exemplares, com rico aparato de notas e referências recentes.

Enumero a seguir autores e temas abordados no dossiê temático "Museus de fotografias documentais": Elisabeth Edwards discorre sobre o papel das fotografias no desenvolvimento do conceito de história local, nas bibliotecas públicas da Inglaterra; Éléonore Challine trata das vicissitudes da própria ideia de musev em torno do Musée des photographies documentaires de Paris, entre 1894 e 1907, fundado por Léon Vidal, para ser um lugar de acumulação ilimitada de imagens destinadas à disseminação impressa; Christian Joschke analisa as diferenças de tradições culturais reveladas na disparidade de documentos fotográficos coletados em vários países europeus a partir dos anos 1880, destacando as redes de fotógrafos amadores, e as especificidades das coleç̃oes regionais (sobretudo na Alemanha); Tiziana Serena trata do caso italiano, das relações entre os museus de arte e a formação dos museus de fotografias documentais, indissociáveis da política de conhecimento do patrimônio artístico no seu país, no começo do século XX; Luce Lebart estuda o Primeiro Congresso Internacional da Documentação Fotográfica, ocorrido em Marselha, em 1906, seguindo os ideais internacionalistas do esperanto, em busca de uma coordenação universal dos arquivos fotográficos; Teresa Castro analisa o cruzamento conceitual
4. Cf. o dossiê de imprensa das Éditions Macula, In Études Photographiques, n. 35, junho de 2017, último número impresso dessa revista, como que abrindo passagem para Transbordeur, que certamente assumirá seu lugar.

5. Expressões do Editorial citado.

6. A expressão é de Michel Lesourd, no catálogo da exposição "Autour du monde: Jean Brunhes, regards d'un géographe, régards de la géographie”, 1993, retomada recentemente por BESSE, Jean-Marc, "Le panorama. Voir et connaître au XIXe siècle", In MADELINE, Laurence e BOUILLER, Jean-Roch, J'aime les panoramas. S'aproprier le monde, catálogo da exposição, Paris/Marseille/ Genève, 2015. 
dos termos "atlas" e "arquivos do mundo" no estudo de caso dos Archives de la parole (191 1-1924), e dos Archives de la planète (1912-1931), que surgem graças ao desenvolvimento de novas técnicas de registro e reprodução mecânica; e finalmente, Béatrice de Pastre busca os pontos comuns da criação dos museus de fotografia documental e os arquivos da produção cinematográfica dos irmãos Lumière, no âmbito das "enciclopédias visuais" das sociedades Gaumont/Pathé.

Na seção "Coleções" escrevem: Frank Kessler e Sabine Lenk, sobre a coleção virtual de placas de lanterna mágica da empresa Ed. Liesegang na Alemanha, na segunda metade do século XIX, voltada para a educação pela imagem, de que restam apenas os catálogos de venda; Valérie Perlès analisa a rica documentação dos Archives de la planète, no Musée Départamental Albert Kahn, seu diálogo com a geografia humana e a etnologia, além da reestruturação do museu e usos atuais da massa de cromos, filmes e registros sonoros coletados por Kahn e equipe; e Nicolas Schätti trata da obra de quatro gerações da família de fotógrafos Boissonnas, de 1860 a 1980, fonte excepcional para a história da fotografia, cujos arquivos foram doados à Biblioteca de Genebra em 2011.

Na seção "Varia" destaca-se o artigo de Alessandra Ronetti sobre "um estranho instrumento em voga no século XIX, o chromatrope, uma rosácea óptica, espécie de lanterna mágica com cores gritantes que produzia fogos de artifício nas projeções" (assim mencionado na resenha do jornal Libération, de 25/02/20 17); segue-se o artigo de Bernd Stiegler sobre a racionalização dos gestos fotografados por Frank Bunker Gillbreth, o "Taylor" da fotografia, e suas experimentações visuais entre 1910-1920; Romy Golan refere-se às performances ou intervenções estéticas de artistas e fotógrafos na cidade de Como, em 1969, concentrando-se na análise do photo-book Campo Urbano então elaborado, e sugere flash-backs com outras temporalidades da história (a ser feita) de episódios de participação no espaço urbano; C. Ângelo Micheli, historiador da arte africana, assina o último artigo da seção sobre retratos fotográficos funerários dos Éwé, prática originada dos Yorubá para celebrar os mortos, que se democratizou na contemporaneidade.

Segue-se a seção "Leituras" com resenhas de livros editados a partir de 2012, entre os quais destaco os seguintes autores e títulos: Clément Cheroux, Avant l'avant-garde. Du jeu en photographie, 1890-1940, 2015; André Gunthert, L'image partagée, La photographie numérique, 2015; T. Galifot, U. Pohlmann, M. Robert (dir.) Qui a peur des femmes photographes? 1839-1945, 2015; Gregg Mitman, Kelley Wilder (dir.) Documenting the World. Film, Photography and the Scientific Record, 2016; Alessandra Mauro (dir.) Photoshow. Landmark Exhibitions that Defined the History of Photography, 2014. 
Tantas questões significativas pesquisadas a fundo e sob indicações recentes da bibliografia internacional contrastam com as generalidades de alguns setores do mercado editorial e de mostras de fotografias hoje, apoiadas, não raro, em textos vazios, alheios à historiografia e contextualização das mesmas. A revista Transbordeur. Photographie, Histoire, Société, dado seu olhar histórico, erudito e crítico da cultura visual em suas relações pluridisciplinares, certamente interessará aos leitores atentos dos Anais do Museu Paulista, cujas páginas já registraram artigos que marcaram época no âmbito da história da fotografia e seus acervos, trazendo enfoques inéditos e posturas metodológicas refletidas, referências de pesquisas e combates pelo estudo e salvaguarda dos arquivos, museus e coleções fotográficas do país.

Artigo apresentado em 29/08/2017. Aprovado em 10/11/2017.

All the contents of this journal, except where otherwise noted, is licensed under a Creative Commons Attribution License

\section{(cc) BY}

